«Системні технології» 2 (127) 2020 «System technologies»

DOI 10.34185/1562-9945-2-127-2020-04

УДК 004.93’1

Н.Л. Дорош, Т.М. Фененко

\title{
ДОСЛІДЖЕННЯ ДЕСКРИПТОРІВ ЩОДО РОЗПІЗНАВАННЯ ЦИФР НАБОРУ MNIST
}

Анотація. Кращі результати розпізнавання цифр отримані на основі нейронних мереж $i$ мають помилку менше 1\%. Успішні алгоритми розпізнавання, в тому числі і глибокого навчання, приховані від користувача і складні в описі, тому не втратили свою актуальність алгоритми на основі дескрипторів. Метою роботи є вибір та дослідження дескриnторів для розпізнавання набору MNIST. Виконано розпізнавання цифр на основі 12 дескрипторів із застосуванням моделей з бібліотеки Scikit-Learn Python. 3а результатами розпізнавання методом к-середніх з'ясовано, що доцільно обрати 8 дескрипторів.

Ключові слова: розпізнавання, цифри рукопису MNIST, дескриптори, Ху-моменти, гістограми, Python, Scikit-Learn, метод k-середніх

Постановка проблеми. Робота присвячена вирішенню задачі розпізнавання цифр. Актуальність дослідження пов'язана $з$ практичною проблемою і представляє інтерес в багатьох сферах діяльності людини. Наприклад, існує проблема розпізнавання номерів автомобілів, вагонів та інших об’єктів, які отримані з використанням відеозйомки. Але безлічі зображень, що представляють інтерес в тому, або іншому додатку, не належать до класу множин, ретельно вивчених у процесі багатовікових математичних досліджень. Істотні позитивні результати з розпізнавання зображень не можуть бути отримані на підставі лише загальних рекомендацій теорії розпізнавання. Необхідно вивчати і враховувати виняткову специфікацію зображення, як об'єкта формального аналізу [1,2]. В роботі проведено аналіз дескрипторів, які були використані в вирішенні задачі розпізнавання цифр рукопису.

Аналіз останніх досліджень і публікацій. На підставі результатів двадцятирічних досліджень можна переконатися, що проблема розпізнавання цифр хоча і добре вивчена, але до теперішнього часу представ-

(C) Дорош Н.Л., Фененко Т.М., 2020 


\section{«Системні технологіï» 2 (127) 2020 «System technologies»}

ляє чималий інтерес. $€$ велика кількість робіт, присвячених розпізнаванню рукописних цифр, які представлені зображеннями [3-7]. При цьому використовуються різні алгоритми класифікації, застосування яких складається 3 наступних етапів [8]:

1-отримати дані (вивчити, проаналізувати і візуалізувати для розуміння їх сутності);

2 - зробити попередню обробку даних: масштабування, перетворення даних;

3 - вибрати модель розпізнавання;

4 - навчити модель на навчальних даних;

5 - перевірити модель на тестовому наборі даних;

6 - оцінити точність роботи моделі.

Таким чином, перш, ніж перейти до застосування алгоритму, необхідно провести збір і підготовку даних. Цей процес досить трудомісткий. Використання наборів даних NIST і MNIST [9] дозволило спростити роботу з підготовки даних і одразу перейти до алгоритмів розпізнавання. У набори MNIST кожна цифра є зображенням, яке являє собою квадрат 28 на 28 пікселів. Усього набор містить 70000 зображень, з яких 60000 використовується для навчання моделі, а 10000 - для її перевірки. Є десять цифр або десять класів. В результаті розпізнавання видається помилка, яка є оцінкою точності.

В [6] показано зведену таблицю результатів класифікації різними алгоритмами на наборі MNIST. Кращі результати розпізнавання мають помилку менше 1\%. Вони отримані із застосуванням великих згортальних нейронних мереж [7]. Успішні алгоритми розпізнавання, в тому числі і глибокого навчання, приховані від користувача і складні в описі, тому не втратили свою актуальність алгоритми розпізнавання на основі дескрипторів.

Мета дослідження. Метою роботи є дослідження дескрипторів і зменшення їх кількості для розпізнавання цифр MNIST з застосуванням бібліотек системи Python.

Викладення основного матеріалу дослідження. При виборі найбільш інформативних ознак необхідно враховувати як властивості 46 
«Системні технології» 2 (127) 2020 «System technologies»

самих об'єктів, так і можливості роздільної здатності первинних формувачів сигналу зображення. Важливою особливістю більшості геометричних ознак є інваріантність щодо розвороту зображення об'єкта, а шляхом нормування геометричних ознак досягається інваріантність щодо масштабу зображення об'єкту. Для розпізнавання цифр рукопису MNIST було обрано набор з 12 дескрипторів, які запропоновані [10] стосовно розпізнавання зображень, а саме: сім перших моментів Н1, H2, H3, H4, H5, H6, H7 [11] і ще п'ять - En (число Ейлера), Ех (коефіцієнт заповнення), Ес (ексцентриситет), Yn, Xn (координати центру ваги), які обрані на підставі аналізу морфологічних ознак об'єкту [12].

Для розширення інформації про властивості дескрипторів проведено аналіз їх гістограм, які наведені на рисунку 1 (для навчального набору) і рисунку 2 (для тестового набору).

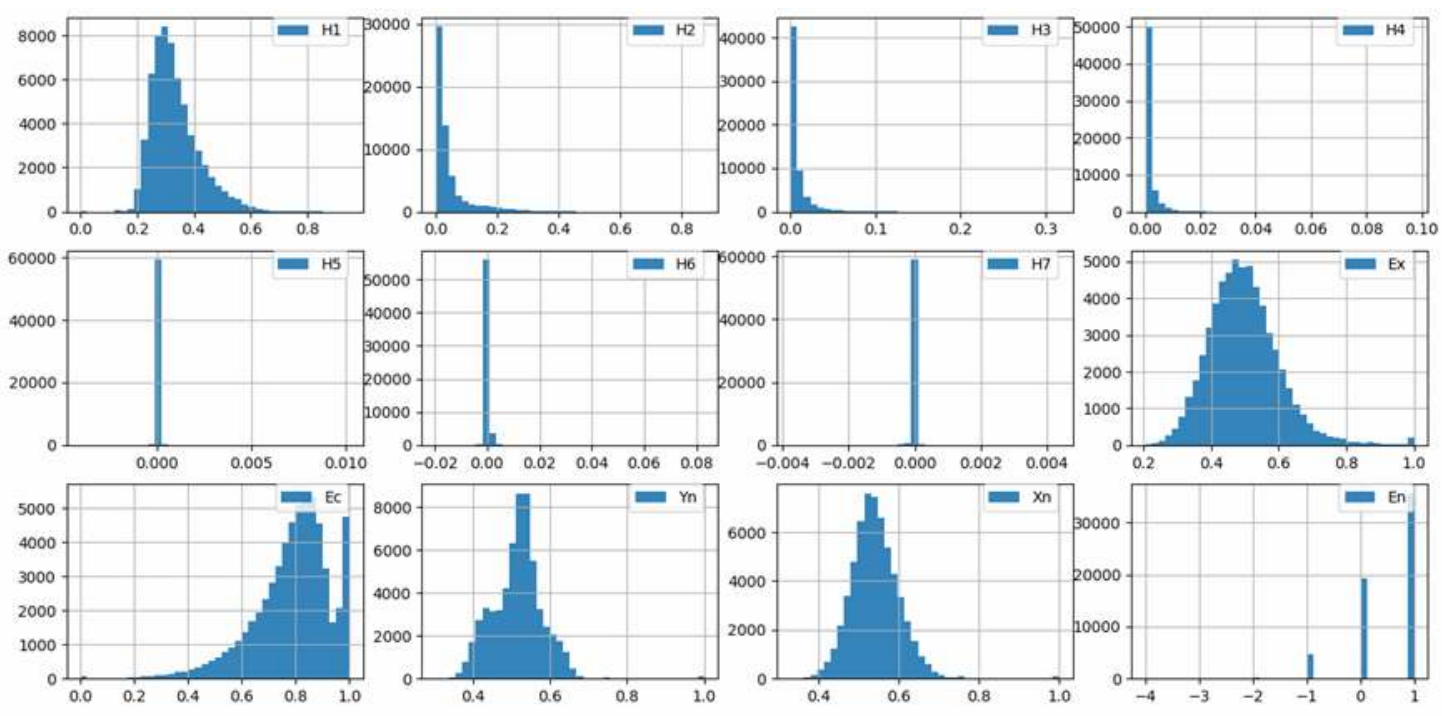

Рисунок 1 - Гістограми дескрипторів для навчального набору (60000) 
«Системні технології» 2 (127) 2020 «System technologies»
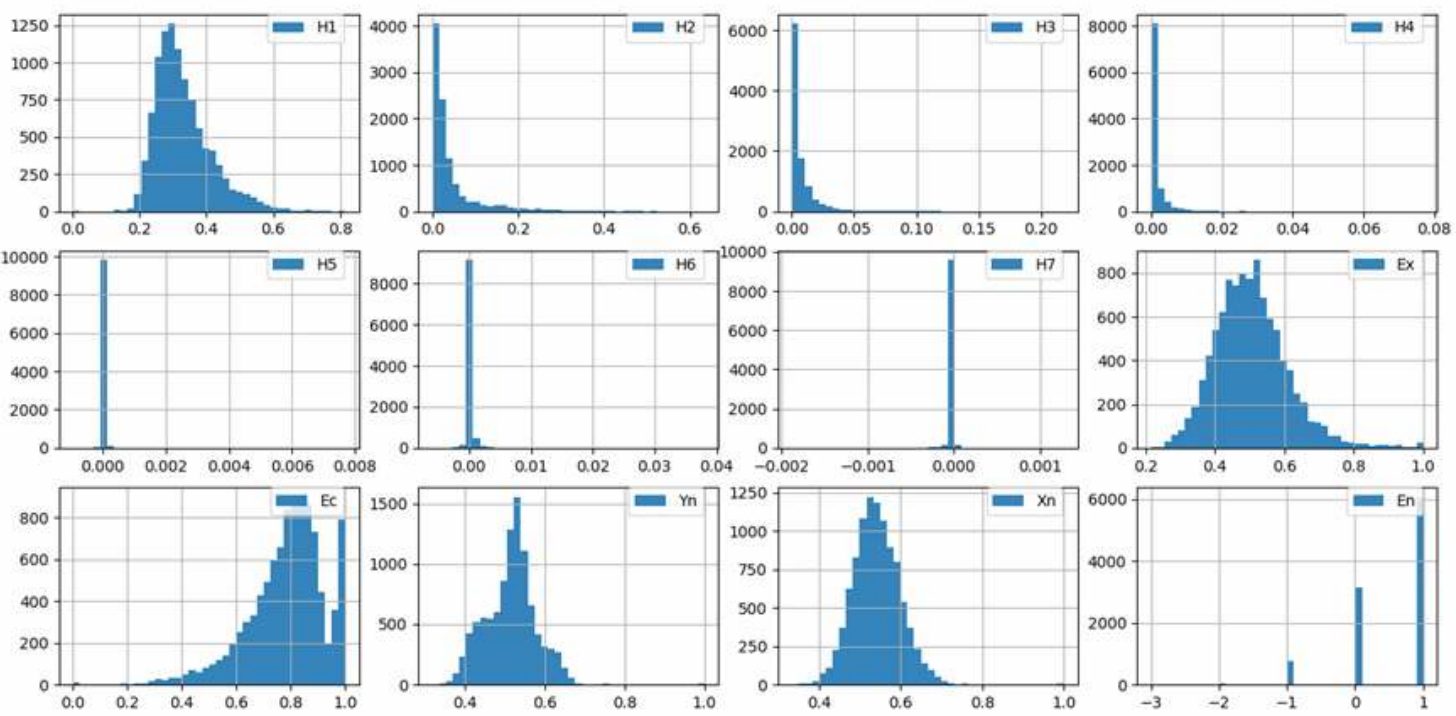

Рисунок 2 - Гістограми дескрипторів для тестового набору (10000)

На основі аналізу гістограм дескрипторів, який можна вважати попереднім, з'ясовано:

- гістограми відповідних дескрипторів в навчальному та тестовому наборах даних мають схожу конфігурацію;

- розподіл даних на гістограмах відрізняється від нормального, отже, для розпізнавання не підходить алгоритм «Наївний Байєс»;

- значення дескриптора Н5 практично для всіх точок нульове;

- небагато значень дескрипторів Н6 і Н7 відрізняються від нуля.

3'ясуємо, скільки зображень з навчального та тестового набору цифр відповідають таким значенням: H5> 0,005; H6> 0,02; abs (H7)> 0,0037 (цифрові значення обрані інтуїтивно по гістограмі навчального набору даних).

Таким чином, у наборі рукописних цифр для навчання і тестування (70000) є мала кількість зображень (7), для яких значення дескрипторів Н5, H6, Н7 з певною точністю відрізняється від нуля. Можна припустити, що ці сім зображень $є$ шумом (брак).

Проведено розпізнавання цифр із застосуванням класифікатора на основі методу k-середніх з n_neighbors = 10 бібліотеки Scikit-Learn системи Python. 
«Системні технології» 2 (127) 2020 «System technologies»

Точність моделі з набором 12 дескрипторів на тестових даних становить $78,15 \%$.

Для того, щоб дізнатися, де модель помиляється можна використовувати матрицю відмінностей (рисунок 3), обчислити яку можна за допомогою бібліотеки Scikit-Learn, а візуалізувати за допомогою Seaborn. B роботі точність розпізнавання виконана з використанням перехресної перевірки.

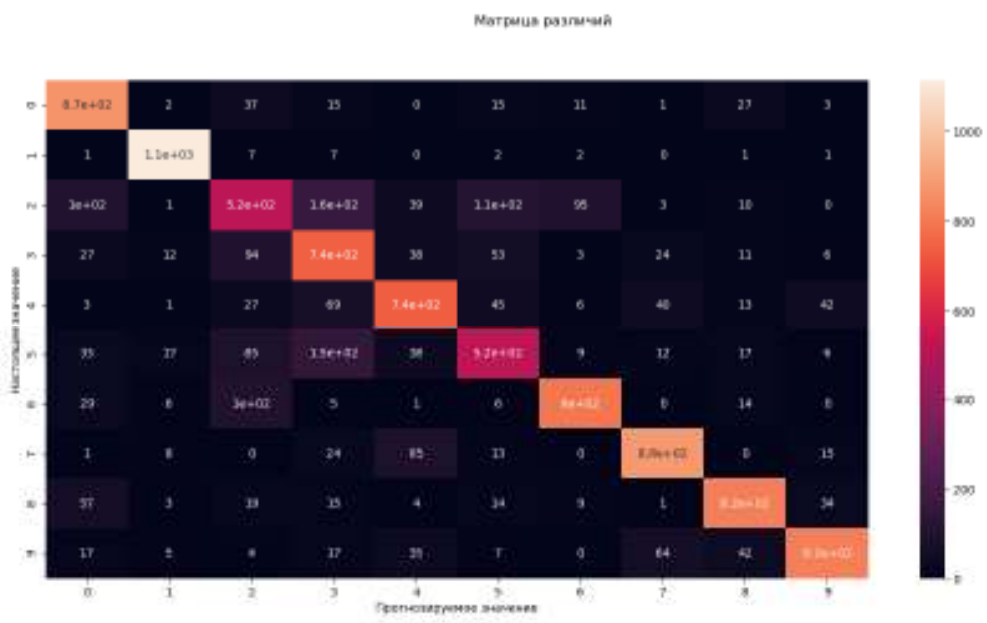

Рисунок 3 - Матриця відмінностей

Проведемо додаткові дослідження 3 використанням методу kсередніх для перевірки розумності вибору всіх 12 дескрипторів. Результати розпізнавання схематично показані на рисунку 4.3 рисунку 4 видно, що точність розпізнавання на основі 12 дескрипторів становить 78,14\% і $€$ найвищою серед наявних варіантів.

Попередній аналіз дескрипторів, давав підстави припустити, що дескриптори Н5, H6 і Н7 не вносять вклад в якість розпізнавання заданого тестового набору цифр методом k-середніх. Це припущення виправдано. Після додавання цих дескрипторів точність залишалася 46,37\%. Також необхідно виключити з набору Ес. Після додавання Ес точність зменшилась до 47,44\% (була 49,18\%).

На рисунку 5 наведені результати розпізнавання методом kсередніх для всіх 12 дескрипторів, 3 набором 39 дескріпторів (без Н5, Н6, H7) і з набором $з 8$ дескрипторів (без Н5, Н6, Н7 і Еc). 
«Системні технології» 2 (127) 2020 «System technologies»

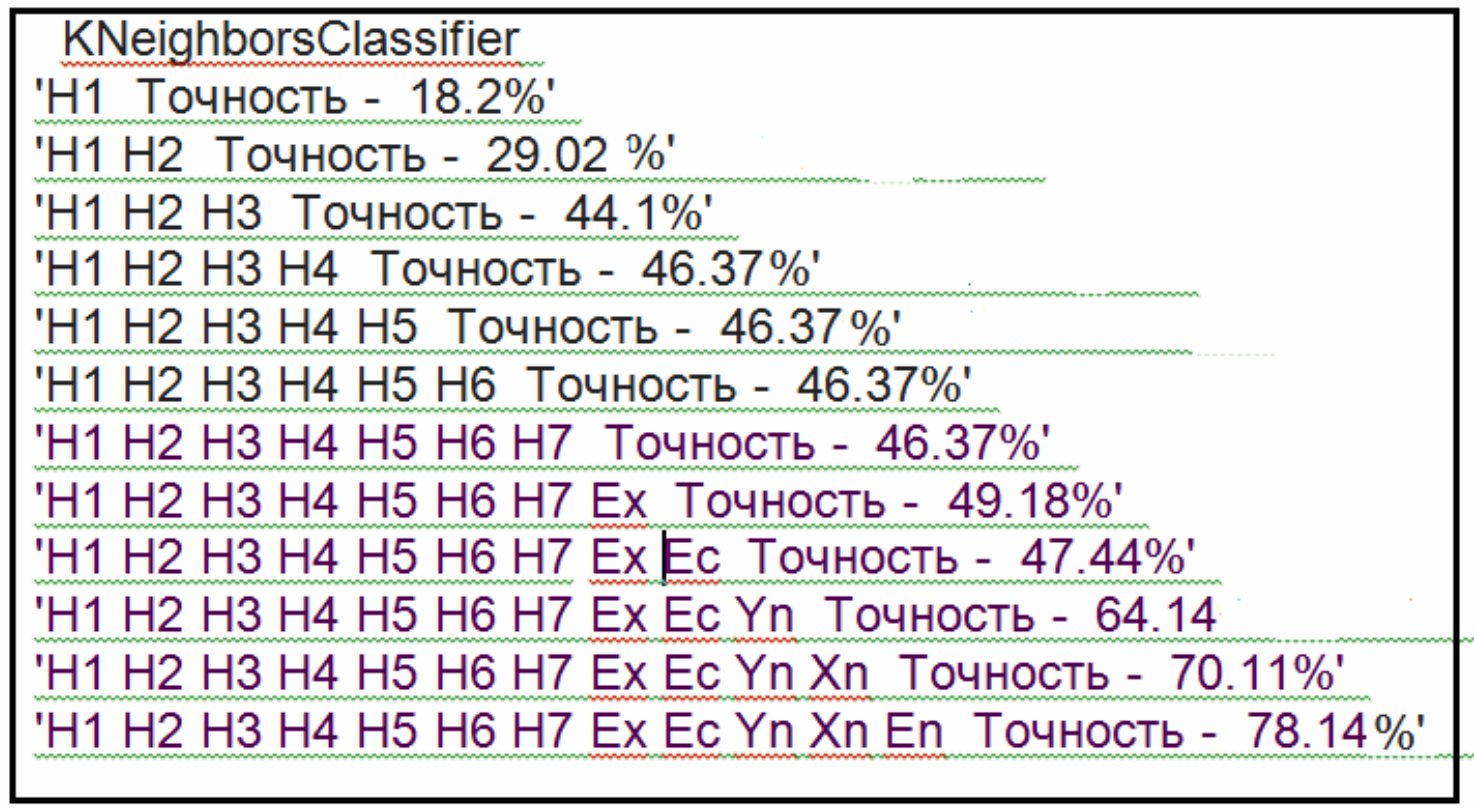

Рисунок 4 - Результати розпізнавання з різним набором дескрипторів

Як видно з рисунку 5 точність розпізнавання тестового набору цифр на підставі набору H1, H2, H3, H4, Ex, Yn, Xn, En (виключили H5, H6, H7, Ес) навіть поліпшилась і становить 78,58\%. Таким чином в набір дескрипторів увійшло 8 елементів замість 12 .

\begin{tabular}{|l|l|}
\hline 'H1 H2 H3 H4 H5 H6 H7 Ex Ec Yn Xn En Точность - 78.14\%' \\
'H1 H2 H3 H4 Ex Ec Yn Xn En Точность - 78.14\%' \\
'H1 H2 H3 H4 Ex Yn Xn En Точность - 78.58\%' \\
\hline
\end{tabular}

$$
\begin{gathered}
\text { Рисунок } 5 \text { - Результати розпізнавання } \\
\text { з вибірковим набором дескрипторів }
\end{gathered}
$$

Висновки. Проведено дослідження дескрипторів, визначені статистичні характеристики та гістограми щодо наборів цифр набору MNIST (навчання та тестування). На основі досліджень зроблено ряд припущень.

Проведено розпізнавання рукописних цифр набору MNIST з використанням класифікатора на основі методу k-середніх з n_neighbors $=10$. Використано набори дескрипторів з 12, які було обрано. Точність розпі- 
«Системні технології» 2 (127) 2020 «System technologies»

знавання $-78,14 \%$, оцінка точності проведена з використанням перехресної перевірки.

Допущення про виключення з набору дескрипторів Н5, Н6, Н7 підтвердилися, було також з'ясовано, що необхідно виключити з набору Ес.

Таким чином, для розпізнавання набору рукописних цифр методом k-середніх 3 n_neighbors $=10$ доцільно взяти 8дескрипторів замість 12. Виключити п'ятий, шостий і сьомий Ху-моменти і ексцентрісітет. Точність розпізнавання склала $78,58 \%$ проти $78,14 \%$.

\section{ЛИТЕРАТУРА / ЛІТЕРАТУРА}

1. Шлезингер М., Главач В. Десять лекций по статистическому и структурному распознаванию. - К.: Наукова думка, 2004. - 545 с.

2. Барсегян А. А., Куприянов М. С., Степаненко В.В., Холод И.И. Методы и модели анализа данных: OLAP и Data Mining, - СПб.: БХВ-Петербург, 2004. - 336c.

3. Плас Дж. Вандер. Python для сложных задач: наука о данных и машинное обучение. - СПб.: Питер, 2018. - 576 с.

4. Нейронные сети с самоорганизацией в задачах классификации и обработки зображений / Г.А. Ососков, С.Г. Дмитриевский, А.В. Стадник // Искусств. интеллект. - 2004. - № 3. - С. 574-586. - Библиогр.: 6 назв. - рус. 5. Дорош Н. Л., Храпач Ю. А. Программное средство для распознавания цифр на изображениях// Материалы международной научной конференции «Интеллектуальные системы принятия решений и проблемы вычислительного интеллекта» (ISDMCI'2012). - Херсон: ХНТУ, 2012. С. 353-355.

6. MNIST. Who is the best in MNIST? [Електронний ресурс] - Режим доступу. - URL:

https://rodrigob.github.io/are_we_there_yet/build/classification_datasets_resu lts.html /(дата звернення 18.10.2019)

7. Распознавание рукописных цифр с использованием сверточных нейронных сетей в Python c Keras [Електронний ресурс] - Режим доступу. URL: 
«Системні технології» 2 (127) 2020 «System technologies»

https://www.machinelearningmastery.ru/handwritten-digit-recognitionusing-convolutional-neural-networks-python-keras // (дата звернення 18.10.2019).

8. Жерон, Орельен. Прикладное машинное обучение с помощью ScikitLearn и TensorFlow: концепции, инструменты и техники для создания интеллектуальных систем./Пер. с англ. - СПб.: ООО "Альфа-книга, 2018. $-688 \mathrm{c}$.

9. The MNIST database of handwritten digits. [Електронний ресурс] - Режим доступу. - URL: http://yann.lecun.com/exdb/mnist/ /(дата звернення 18.10.2019).

10. Гонсалес Р., Вудс Р., Эддинс С. Цифровая обработка изображений в среде MatLab. M: Техносфера, 2006. - 616 с.

11. Hu_moments_in_Python. [ Електронний ресурс] - Режим доступу. URL:https://github.com/adailtonjn68/hu_moments_in_python/blob/master/hu _moments.py/ (дата звернення 24.11.2019).

12. Яне Б. Цифровая обработка изображений. М: Техносфера, 2007.-584 с.

\section{REFERENCES}

1. Shlezinger M., Glavach V. Desyat lektsiy po statisticheskomu i strukturnomu raspoznavaniyu. - K.: Naukova dumka, 2004. - $545 \mathrm{~s}$.

2. Barsegyan A. A., Kupriyanov M. S., Stepanenko V.V., Holod I.I. Metodyi i modeli analiza dannyih: OLAP i Data Mining, - SPb.: BHV-Peterburg, 2004. 336s.

3. Plas Dzh. Vander. Python dlya slozhnyih zadach: nauka o dannyih i mashinnoe obuchenie. - SPb.: Piter, 2018. - $576 \mathrm{~s}$.

4. Neyronnyie seti s samoorganizatsiey v zadachah klassifikatsii i obrabotki izobrazheniy / G. A. Ososkov, S. G. Dmitrievskiy, A. V. Stadnik // Iskusstv. intellekt. - 2004. - \# 3. - S. 574-586. - Bibliogr.: 6 nazv. - rus.

5. Dorosh N. L., Hrapach Yu. A. Programmnoe sredstvo dlya raspoznavaniya tsifr na izobrazheniyah// Materialyi mezhdunarodnoy nauchnoy konferentsii «Intellektualnyie sistemyi prinyatiya resheniy i problemyi vyichislitelnogo intellekta» (ISDMCI'2012). - Herson: HNTU, 2012. - S. 353-355. 
«Системні технології» 2 (127) 2020 «System technologies»

6. MNIST. Who is the best in MNIST? [Electronic resource] - Access mode.URL:https://rodrigob.github.io/are_we_there_yet/build/classification_datasets _results.html /( date of appeal 18.10.2019)

7. Raspoznavanie rukopisnyih tsifr s ispolzovaniem svertochnyih neyronnyih setey v Python s Keras [Electronic resource] - Access mode.- URL:

https://www.machinelearningmastery.ru/handwritten-digit-recognition-

using-convolutional-neural-networks-python-keras//( date of appeal 18.10.2019)

8. Zheron, Orelen. Prikladnoe mashinnoe obuchenie s pomoschyu ScikitLearn i TensorFlow: kontseptsii, instrumentyi i tehniki dlya sozdaniya intellektualnyih sistem./Per. s angl. - SPb.: OOO "Alfa-kniga, 2018. - 688 s.

9. The MNIST database of handwritten digits. [Electronic resource] - Access mode.- URL: http://yann.lecun.com/exdb/mnist/ / (date of appeal 18.10.2019).

10. Gonsales R., Vuds R., Eddins S. Tsifrovaya obrabotka izobrazheniy v srede MatLab. M: Tehnosfera, 2006. - 616 s.

11. Hu_moments_in_Python. [Electronic resource] - Access mode. URL:https://github.com/adailtonjn68/hu_moments_in_python/blob/master/hu _moments.py/( date of appeal 24.11.2019).

12. Yane B. Tsifrovaya obrabotka izobrazheniy. M: Tehnosfera, 2007. - 584 s.

Received 07.02.2020. Accepted 11.02.2020

Исследование дескрипторов для распознавания цифр набора MNIST

Проведены выбор и исследование дескрипторов для набора MNIST. Выполнено распознавание цифр на основе 12 дескрипторов с применением моделей из библиотеки Scikit-Learn Python. Получены результаты сравнительного анализа распознавания с разным количеством дескрипторов методом к-средних, на основании которого установлено, что целесообразно перейти к группе дескрипторов из 8 элементов.

\section{Research of descriptors for digit recognition of MNIST dataset}

The work is dedicated to solving the task of digit recognition.

Based on the results of twenty years of research, we can verify that the problem of digit recognition, even being well studied, is still of considerable interest.

The MNIST set has become a test set one and is used by many authors for testing of recognition algorithms. In the work "MNIST. Who is the best at MNIST" there is a spreadsheet with result of handwritten numbers recognition made by different algorithms, which are combined into groups. 
«Системні технологіï» 2 (127) 2020 «System technologies»

The best result of recognition have an error of less than 1\%. They are obtained using neural networks. Successful algorithms of recognition, including deep learning, are hidden from user and they are difficult in description. That is why the descriptor-based recognition algorithm is still relevant.

The goal of the work is the study of influence of descriptors and reduction of their quantity for recognition of MNIST set handwritten numbers

For recognition of the MNIST digits, a set of 12 descriptors was chosen, namely: seven $X$ moments, En (Euler's number), Ex (filling coefficient), Ec (eccentricity), Yn, Xn (coordinates of the center of gravity). Statistical characteristics and histograms in relation to the training and test sets MNIST were determined. Based on their research, a number of assumptions were made.

Digit recognition with usage of classifier based on on $k$-means method with $n$ neighbors $=$ 10 of Scikit-Learn Python system library was done. Preliminary analysis of descriptors gave the reason to assume, that the fifth, sixth and seventh Hu-moments doesn't contribute into result of digit recognition of test set using $k$-means method. This assumption is justified with researches, which showed, that there is a need to exclude eccentricity from the set of descriptors

Thus, for recognition of a set of handwritten digits by the k-means method with $n \_$neighbors $=10$, it is advisable to take 8 descriptors instead of 12 , excluding the fifth, sixth and seventh Hu-moments and eccentricity. Recognition accuracy was $78.58 \%$ compared to $78.14 \%$.

Дорош Наталья Леонидовна - к.т.н., доцент, кафедра информационных технологий и систем, Национальная металлургическая академия Украины.

Фененко Татьяна Михайловна - старший преподаватель, кафедра информационных технологий и систем, Национальная металлургическая академия Украины.

Дорош Наталія Леонідівна - к.т.н., доцент, кафедра інформаційних технологій і систем, Національна металургійна академія України.

Фененко Тетяна Михайлівна - старший викладач, кафедра інформаційних технологій і систем, Національна металургійна академія України.

Dorosh Nataliia - associate professor, department of information technologies and systems, National Metallurgical Academy of Ukraine.

Fenenko Tatyana - senior teacher, department of information technologies and systems, National Metallurgical Academy of Ukraine. 